savages with their luands, or cren with their ignorant tools. As respects the arts and sciences, the ratio between knowledge and ignorance is perhaps still greater. How absurd, then, to content ourselves with imperfect knowledge, so long as that which is more accurate is at our command.

When learning is directed to the preservation of the health and lives of our fellow beings, the preceding remarks apply with redoubled force. Here the passions, except so far as they prove to be a stimulus to exertion, and give a zest to our pursuit, should be laid aside, and self-interest, if under any circuinstances, ought to sleep. We can have no more noble object in view, than to remove and palliate the calamities to which human nature is subject. If any man ought to know the truth in order to be equipped for his calling, it is the physician. If any one feels an ardor for his profession, it ouglit to be the medical practitioner. It is one of the kindest laws of Providence, that industry, benevolence, and skill, in a great measure, carry with them their own reward. There is no satisfaction equal to the consciousness of being able and ready to do gond. The zeal of a true philanthropist ls far different from the fanatical wild-fire of ururuly, selfish passion. It purifies and exalts the nind above everything mean or sordid, and directs all its efforts to objects of practical utility.

It is not proper here to disturb our speculations by attempting to reverse the picture, and it would ill accord with the writer's present feelings to look upon anything but the bright side of the subject. His great desire is for the prosperity of his profession, and, through it, for an amelioration of the sufferings of humanity. His wish is, he could infuse into his younger brethren some part of the ardor which an old man still feels. While dwelling upon the subject, he fancies his age renewed. He recounts with pleasure the many improvenents which have been introduced since his recollection, and is extremely gratified in the superior advantages which the present generation enjoy. All that he could further desire is, that they may improve to the greatest benefit their present privileges, till our happy country is ns much distinguished by the superiority of the medical profession, as it is for the decided excellence of many of its most important institutions.

S.

\title{
CASE OF MORBID APPETITE IN TYPHOUS FEVER.
}

BX A. P. FULLER, M.D.

[Communicated for the Boston Medical and Surgienl Journal.]

L. Glidden, Esq. of this town, aged 48, married, formerly healthy but constitution slender, came under my care in September 1831. Was attacked with the common symptoms of typhous fever; had nausea, loss of appetite, headache-tongue thick coated, white-but little pain, pulse full, not hard nor strong. 5th day, fever increased, but had a good appetite. Was allowed a considerable quantity of farinaceous food ; and finding no inconvenience from the sane, the quantity was daily iucreased.

15 th day.-Fever continues unabated; tongue coated with dense 
white coat ; pulse about 90 ; skin hot and dry ; thirst inconsiderable; secretions large ; no pain ; unable to sit up but little; hallucination of nind ; has a voracious appetite.

His food consisted of two pints of new milk boiled, to which was added half a pint of rice, first boiled soft-making the composition about balf liquid and balf solid. Of this food be tnok daily, for 15 days, 14 pounds avoirdupois by actual weight, and could hardly be satisfied with that. Digestion was good, and bowels were moved without physicstools color of the food he ate-urine high-colored, and in very large quantities-sleep nearly natural-perspiration copious. After fever abated, which was about the 30 th day, appetite began to decline; and when the fever had chiefly left him, he had little or no desire for food. He was restored in a few weeks to gogd health.

Fayelle, Maine, Dic. 3, 1833.

BOSTON MEDICAL AND SURGICAL JOURNAL.

BOSTON, DECEMBER 11,1833 .

\section{PHYSIATRICY.}

Tirs was a favorite term of Hufeland to express the vis medicatrix, in which that physician placed unbounded confidence, and which he regarded in a somewhat more extended light than it is viewed by most pathologists of the day. According to his view, life is one and indivisible ; all which constitutes the organism, whether fluid or solid, is vivified, and above all the blood, a fluid organ, the source and mother of all life in the organism; and all the powers, elements, and relations, in universal nature, the mechanical and chemical even not excepted, are present and active in the animal cconomy, only raised to a higher sphere of existence and peculiarly modified by the vital power.

"The cardinal point on which everything in medioine, theory as well as practice, rests, is the relation and different reaction of the vital power, in connection with the different organization by which it acts, and the dead (chemical and mechanical) natural powers, subordinate to it. This reaction is the foundation of all diseases and their modifications, of all healing power and healing effort of nature in diseases, of all the efficacy of remedies, and thus also of all practical medicine, which, indeed, consists of nothing further than in taking advantage of, supporting, and directing this reaction of the natural power. The same powers and laws of the animate organic body, by which disease is formed, are those also by which it is removed, transformed, mittgated, and the equilibrium again restored. As these powers and laws (which I have here begun to develope) are determinate, so is also unity in the whole system of art and its different parts, and, from the same principles, may be derived the right notion, as well of the nature of diseases, as of the modes of operation of remedies, as also rules for healing; as I shall show in my lectures on the doctrine of diseases and remedies, and practical physic."

It would appear from this quotation that Hufoland considered the powers of nature to be operating for the restoration of the system to a state 